\title{
Assessment of the Mental Health Continuum in a Sample of Argentinean Adults
}

\author{
Vanesa C. Góngora' ${ }^{1}$ Alejandro Castro Solano² \\ ${ }^{1}$ National Scientific and Technical Research Council (CONICET), Buenos Aires, Argentina \\ ${ }^{2}$ University of Palermo, Buenos Aires, Argentina \\ Email:vgongo1@palermo.edu
}

How to cite this paper: Góngora, V. C., \& Solano, A. C. (2017). Assessment of the Mental Health Continuum in a Sample of Argentinean Adults. Psychology, 8, 303318 .

https://doi.org/10.4236/psych.2017.83018

Received: November 30, 2016

Accepted: February 10, 2017

Published: February 13, 2017

Copyright $\odot 2017$ by authors and Scientific Research Publishing Inc. This work is licensed under the Creative Commons Attribution International License (CC BY 4.0).

http://creativecommons.org/licenses/by/4.0/ (c) (i) Open Access

\begin{abstract}
The aims of this study are 1) to evaluate the mental health continuum and the dual-continua model classifications in a sample of Argentinean adults; and 2) to compare the mental health prevalence according to demographic variables and the presence of significant psychiatric symptoms. The sample included 627 adults ( $49.8 \%$ males and $50.2 \%$ females). The mean age of participants was 40.62 years old. The Symptom Checklist-90-Revised and the Mental Health Continuum-Short Form were used in the study. A high proportion of adults had flourishing mental health (39.7\%), and only a minority had languishing mental health (5.7\%). Higher mental health was related only to having income. Having any mental disorder significantly decreased mental health status, and individuals were more languishing and less flourishing in all mental disorder categories. Findings showed Argentinean adults to have very good mental health.
\end{abstract}

\section{Keywords}

Mental Health, Assessment, Adults, Argentina, Prevalence

\section{Introduction}

The assessment and development of interventions to promote population-wide well-being are a topic of growing interest and research in psychology. Contemporary theories of well-being focus on the construct of flourishing. Different authors have developed the conceptualization and operationalization of flourishing-Keyes (2002), Diener et al. (2010), Seligman (2011), and Huppert and So (2013)-however, Keyes' $(2002,2005)$ formulation has become the most relevant in terms of development and international research.

Keyes defines flourishing as high levels of emotional, psychological, and social well-being (Keyes, 2005). In this theory, emotional well-being consists of posi- 
tive affect and satisfaction with life; psychological well-being is based on Riffs theory (Ryff, 1989) and includes dimensions of psychological functioning, such as autonomy, personal growth, positive relationships with others, environmental mastery, self-acceptance, and purpose in life; and social well-being builds on Keyes' (1998) conceptualization and describes how well an individual functions in their social life as a member of a larger society, comprising aspects such as social acceptance, social actualization, social contribution, social coherence, and social integration

Flourishing is one of the three diagnostic categories, or levels, in a continuum of positive mental health (Keyes \& Lopes, 2002). The other two categories are languishing and moderate mental health. Languishing is characterized by the poor mental health (low levels of well-being), and it is the opposite of flourishing mental health. While languishing individuals are those who are stuck in life, feeling empty, and whose life lacks interest and engagement, individuals who are neither flourishing nor languishing are classified as moderate mental health. Keyes (2005) considers flourishing as the optimal mental health state.

Studies have shown substantial differences in flourishing prevalence rates among the adult population of diverse countries ranging from $8 \%$ in South Korea (Lim, Ko, Shin, \& Cho, 2013) to $72.5 \%$ in Canada (Gilmour, 2014), as well as $18 \%$ in the US (Keyes \& Grzywacz, 2005), 20\% in South Africa (Keyes et al., 2008), 26\% in Poland (Karaś, Cieciuch, \& Keyes, 2014), 28\% in Italy (Petrillo, Capone, Caso, \& Keyes, 2015), 43\% in China (Yin, He, \& Fu, 2013), and 68\% in France (Salama-Younes, 2011). In most of these countries, the categories of moderate and flourishing mental health represent the majority of the adult population, while the languishing mental health obtained rates have ranged from 1.5\% in Canada to 21.2\% in South Korea (Gilmour, 2014; Lim et al., 2013).

Keyes (2002) not only proposed a mental health classification, but also integrated it with the traditional classification of mental disorders according to the DSM model. The author developed the dual-continua model, in which one continuum indicates the levels of mental health (flourishing, moderate, and languishing mental health) and the other continuum indicates the presence or absence of mental illness (Keyes, 2007).

One of the main assumptions of the dual-continua model is that the absence of mental disorder does not imply the presence of mental health. For Keyes (2005), mental health and mental illness are two different but related variables. Numerous empirical studies have supported this postulation (Gilmour, 2014; Keyes, 2005; Keyes et al., 2008; Lim et al., 2013; Petrillo et al., 2015; Yin et al., 2013). Complete mental health corresponds to the state of flourishing in which there are high levels of emotional, psychological, and social well-being as well as absence of mental illness. Any other state of dual continua classification implies a limitation on the individual's functioning.

It may happen that a person with a flourishing mental health has an episode of mental illness (flourishing and mental illness); however studies have shown that this category corresponds to a small proportion of population not exceeding a 
5.5\%. In general, people with mental disorders are placed in the categories of moderate or languishing mental health (Gilmour, 2014; Keyes, 2007; Lim et al., 2013; Yin et al., 2013).

Keyes (2002) argued that demographic variables such as sex, age, level of educational, and occupation may affect ongoing mental health. However, international studies have found mixed results. With regard to sex, studies have found higher levels of mental health in Italian and American men (Keyes, 2005; Petrillo et al., 2015), in Dutch women (Westerhof \& Keyes, 2010), and no differences between Canadian, Korean, and Chinese men and women (Gilmour, 2014; Lim et al., 2013; Yin et al., 2013). In terms of age groups, the results are even more contradictory. Higher levels of mental health have been found in Korean and Polish young adults, older aged Americans and Canadians, and middle-aged Italian adults (30 - 60 years), but no differences in Chinese and Dutch adults (Gilmour, 2014; Karaś et al., 2014; Keyes, 2005; Lim et al., 2013; Petrillo et al., 2015; Westerhof \& Keyes, 2010; Yin et al., 2013). In addition, higher educational level has been associated with higher mental health in adults in China, Poland, America, and Korea (Karaś et al., 2014; Keyes \& Lopez, 2002; Lim et al., 2013; Yin et al., 2013). No significant differences in mental health levels were found by type of employment in US nor Canadian adults; however, Chinese independent workers show higher mental health than do employed people. Being unemployed has been shown to be associated with lower levels of mental health in American and Canadian adults. In line with these findings, Korean housewives showed lower levels of mental health (Gilmour, 2014; Keyes, 2005; Lim et al., 2013).

Research has supported the hypothesis that adults with flourishing mental health function better as compared to adults with moderate mental health, who in turn function better than languishing individuals. Flourishing mental health has been associated with a decrease in work performance and increased use of health services (Keyes \& Grzywacz, 2005); fewer diseases and chronic physical conditions (Keyes, 2005); reduced risk of various causes of death (Keyes \& Simoes, 2012); and higher levels of psychosocial functioning (Karaś et al., 2014; Keyes, 2007; Petrillo et al., 2015). In addition, flourishing was also associated with lower incidence of mental illnesses and lower levels of depression, generalized anxiety, suicidality, substance abuse, alcohol dependence, and panic disorder in adults (Gilmour, 2014; Karaś et al., 2014; Keyes, 2005; Keyes, Dhingra, \& Simoes, 2010; Keyes et al., 2011; Petrillo et al., 2015; Yin et al., 2013).

To date, two previous studies in Latin America countries have examined the psychometric properties of the Mental Health Continuum-Short Form (MHC$\mathrm{SF}$ ), in Argentina and in Brazil (Lupano Perugini, De la Iglesia, Castro Solano, \& Keyes, 2016; Machado \& Bandeira, 2015). Both studies have shown good evidence of validity and reliability of the instrument in adult populations; however, none have investigated the prevalence of the mental health continuum state and the dual-continua model classification in a sample of Latin American adult population. Accordingly, the aims of this study were: 1) to evaluate mental health 
using the mental health continuum and the dual-continua model classifications in a sample of Argentinean adult population; and 2) to compare the mental health prevalence according to demographic variables (sex, age, employment type, educational level, having children, place of birth) and the presence of significant psychiatric symptoms (depression, anxiety, somatization, phobic anxiety, and obsessions and compulsions).

According to the more consistent findings in aforementioned international studies, we expected that flourishing and moderate mental health will be the most prevalent categories in the mental health continuum among Argentinean adults. In addition, we expected to observe higher levels of mental health in adults with higher educational level and in those who receive salary. Moreover, adults with significant depressive, anxious, somatic, obsessive-compulsive, or phobic symptoms were expected to have lower levels of mental health, being placed mainly in the categories of languishing and moderate mental health. Only a small percentage of that group was expected to have flourishing mental health.

\section{Method}

\subsection{Sample}

The sample included 627 community-dwelling adults, 312 males (49.8\%) and 315 females $(50.2 \%)$. The mean age was 40.62 years $(S D=14.33)$, ranging from 18 to 85 years. Sample demographic characteristics are presented in Table 1 . Participation in the study was voluntary, consented, and anonymous. No economic contribution was given in exchange. Participants were recruited as convenience sample by advanced psychology students who were conducting their research practices during their undergraduate studies.

\subsection{Instruments}

Symptom Checklist-90-Revised (SCL-90-R). This is a 90-item checklist (Derogatis, 1977) used to measure nine sets of psychological symptoms: Somatization, Obsessive-Compulsive, Interpersonal Sensitivity, Depression, Anxiety, Hostility, Phobic Anxiety, Paranoid Ideation, and Psychoticism. The SCL-90-R also contains a Global Severity Index (GSI), which is used to estimate the "general psychiatric status" of a patient. The SCL-90-R uses a 5-point scale ( $1=$ "no problem" to 5 = "very serious") to measure the extent to which they have experienced the listed symptoms in the last 7 days. Studies with the Argentinean adaptation of the checklist have sown adequate internal consistency for all scales (all as $>.75$ ) and have replicated the original factorial structure (Casullo, 2004; Sanchez \& Ledesma, 2009). Internal consistency for all items in this sample was $\alpha=.97$.

Mental Health Continuum-Short Form (MHC-SF). This is a 14-item scale (Keyes, 2005) that measures emotional (3 items, e.g., "satisfied with life"), psychological (6 items, e.g., "that you had warm and trusting relationships with others"), and social (5 items, e.g., "that you had something important to contribute to society") well-being on a 5-point scale, ranging from 0 ("never") to 5 
Table 1. Demographic characteristics of sample $(\mathrm{N}=627)$.

\begin{tabular}{|c|c|c|c|}
\hline \multicolumn{2}{|c|}{ Demographic characteristic } & $\mathrm{n}$ & $\%$ \\
\hline \multirow{2}{*}{ Sex } & Male & 312 & 49.8 \\
\hline & Female & 315 & 50.2 \\
\hline \multirow{5}{*}{ Age groups } & $18-29$ & 167 & 26.6 \\
\hline & $30-39$ & 156 & 24.9 \\
\hline & $40-49$ & 124 & 19.8 \\
\hline & $50-59$ & 101 & 16.1 \\
\hline & $60+$ & 79 & 12.6 \\
\hline \multirow{4}{*}{$\begin{array}{l}\text { Highest } \\
\text { educational level }\end{array}$} & Basic & 58 & 9.3 \\
\hline & Middle & 289 & 46.1 \\
\hline & Tertiary/University & 242 & 38.6 \\
\hline & Postgraduate & 38 & 6.1 \\
\hline \multirow{4}{*}{ Place of birth } & Buenos Aires and Surroundings & 432 & 68.9 \\
\hline & Other city Argentina & 114 & 18.2 \\
\hline & Other country & 60 & 9.6 \\
\hline & No Information & 21 & 3.3 \\
\hline \multirow{2}{*}{ Children } & No & 312 & 49.8 \\
\hline & Yes & 315 & 50.2 \\
\hline \multirow{6}{*}{ Employment type } & Employer & 61 & 9.7 \\
\hline & Employee & 344 & 54.9 \\
\hline & Independent worker & 106 & 16.9 \\
\hline & Housekeeping/worker without salary & 25 & 4 \\
\hline & Retired/pensioned & 33 & 5.3 \\
\hline & Unemployed & 58 & 9.3 \\
\hline \multirow{2}{*}{ Salary } & No & 83 & 13.8 \\
\hline & Yes & 544 & 86.2 \\
\hline
\end{tabular}

("every day"). The MHC-SF has been shown to have very good internal consistency (>.70) and discriminant validity among adults in the US, The Netherlands, China, Italy, Iran, Canada, Poland, and South Africa. The three-factor structure of the MHC-SF (emotional, psychological, and social) has been confirmed in all adult samples of international studies (Gallagher, Lopez, \& Preacher, 2009; Gilmour, 2014; Joshanloo, Wissing, Khumalo, \& Lamers, 2013; Karaś et al., 2014; Keyes, 2005; Lamers, Westerhof, Bohlmeijer, ten Klooster, \& Keyes, 2011; Petrillo et al., 2015; Robitschek \& Keyes, 2009; Yin et al., 2013). The Argentinean adaptation of the MHC-SC was used in this study. The validation study has confirmed the three-factor structure of the scale and shown good convergent validity (Lupano Perugini et al., 2016). In the current sample, internal consistencies were $\alpha=.86$ for emotional well-being, $\alpha=.86$ for psychological well-being, and 
$\alpha=.75$ for social well-being.

\subsection{Procedure}

Instruments were administered by advanced students of Psychology as part of their pre-professional practice in the research area. They were instructed to administer the test battery to the general adult population living in the Metropoli$\tan$ area of the City of Buenos Aires. Participants were informed of the purpose of the investigation and signed an informed consent form.

\subsection{Statistical Analysis}

According to the MHC-SC scores, mental health categories were assigned to individuals and relative frequencies for each category were calculated. The same procedure of classification was used to estimate the prevalence of mental health on each demographic variable. Chi-squared were performed to compare the mental health prevalence according to the demographic variables. Based on SCL-90-R risk cut-off points, participants were classified between those with high risk of five specific disorders: depression, anxiety, somatization, phobic anxiety, and obsessions and compulsions and those without risk. Mental health categories were calculated for each clinical group and chi-squared were executed to compare Keyes's categories between individuals with and without each specific disorder. Finally, those individuals who scored high on any of the five SCL-90-R symptom dimensions were classified in the group of individuals with mental disorders. The dual diagnosis classification was performed separating each mental health category: languishing, moderate mental health and flourishing in two groups: one with individuals with a mental disorder and another without a mental disorder.

\section{Results}

\subsection{Categorical Classification of Mental Health}

The categorical classification of Mental Health was based on Keyes's (2005) standard procedure. To be categorized with flourishing mental health, individuals must report experiencing "every day" or "almost every day" on at least one of the three indicators of hedonic well-being and on at least six of the eleven indicators of positive functioning during the past month. Individuals who report low levels (i.e., "never" or "once or twice" during the past month) on at least one sign of hedonic well-being and low levels on at least six signs of positive functioning were classified with languishing mental health. Individuals who were neither flourishing nor languishing were categorized with moderate mental health. The categorical classification of mental health is presented in Table 2.

The majority of the sample was categorized as moderate mental health (54.9\%) or flourishing (39.7\%) and only a 5.4\% was classified as languishing. Taking together the two healthy categories, most of the Argentinean adults (94.6\%) can be classified with good mental health. It should be noticed that an important proportion of the sample was flourishing, being this category almost 
Table 2. Diagnosis of Mental Health for the total sample $(n=627)$ and for SCL-90-R mental disorder categories.

\begin{tabular}{cccccc}
\hline \multirow{2}{*}{ Mental Disorder } & Languishing & $\begin{array}{c}\text { Mod Mental } \\
\text { Health }\end{array}$ & Flourishing & Total \\
\hline Total & $\mathrm{n}$ & 34 & 344 & 249 & 627 \\
& $\%$ & 5.4 & 54.9 & 39.7 & 100 \\
Depression & $\mathrm{n}$ & 13 & 25 & 2 & 40 \\
& $\%$ & 32.5 & 62.5 & 5.0 & 100 \\
Anxiety & $\mathrm{n}$ & 7 & 23 & 4 & 34 \\
& $\%$ & 20.6 & 67.6 & 11.8 & 100 \\
Somatization & $\mathrm{n}$ & 3 & 35 & 4 & 42 \\
& $\%$ & 7.1 & 83.3 & 9.5 & 100 \\
Phobic Anx. & $\mathrm{n}$ & 7 & 35 & 13 & 55 \\
& $\%$ & 12.7 & 61.6 & 23.6 & 100 \\
Obs.Compul. & $\mathrm{n}$ & 6 & 27 & 4 & 37 \\
& $\%$ & 16.2 & 73.0 & 10.8 & 100 \\
\hline & & 12 & 33 & 4 & 49 \\
\hline
\end{tabular}

Note: * two to five diagnosis of mental disorder.

as important as the moderate mentally healthy group.

\subsection{Mental Health Classification and Demographic Data}

The same procedure of mental health categorical classification was followed using the demographic variables as independent variables. Chi-squared were calculated to compare the mental health prevalence according to the demographic variables. The results are shown in Table 3.

No significant differences were found in the mental health categorical classification between men and women $\left(\chi^{2}=.88, \mathrm{df}=2, p=.64\right)$, age groups $\left(\chi^{2}=3.88\right.$, $\mathrm{df}=8, p=.87)$, the level of education attained $\left(\chi^{2}=5.57, \mathrm{df}=6, p=.47\right)$, having children or not $\left(\chi^{2}=2.61, \mathrm{df}=2, p=.27\right)$, or place of birth $\left(\chi^{2}=12.05, \mathrm{df}=5\right.$, $p=.06)$. In this latter variable, the "no information" category had $19.1 \%$ of participants showing languishing mental health, which explains the near-significant finding. As this was a heterogeneous category, a new analysis was performed without "no information". The new results showed that there were clearly no differences in mental health classification according to place of birth $\left(\chi^{2}=4.38\right.$, $\mathrm{df}=4, p=35)$. No significant differences in mental health status were found between different employment type; however, the p-value approached significance $\left(\chi^{2}=17.31, \mathrm{df}=10, p=.07\right)$. A closer examination of the percentages obtained in the classification categories showed a higher proportion of unemployed (12.1\%) and housekeeping/worker without salary (16\%) individuals in the languishing group. Thus, a second analysis was performed, regrouping the em- 
Table 3. Categorical mental health classification according to the demographic variables used in this study.

\begin{tabular}{|c|c|c|c|c|c|c|}
\hline & \multicolumn{2}{|c|}{ Demographic characteristic } & \multirow{2}{*}{$\begin{array}{c}\text { Languishing } \\
34\end{array}$} & \multirow{2}{*}{$\begin{array}{c}\text { Mod } \\
\text { Mental } \\
\text { Health }\end{array}$} & \multirow{2}{*}{$\begin{array}{c}\text { Flourishing } \\
249\end{array}$} & \multirow{2}{*}{$\begin{array}{r}\text { Total } \\
627\end{array}$} \\
\hline & Total & $\mathrm{n}$ & & & & \\
\hline & & $\%$ & 5.4 & 54.9 & 39.7 & 100 \\
\hline \multirow{4}{*}{ Sex } & Male & $\mathrm{n}$ & 16 & 177 & 119 & 312 \\
\hline & & $\%$ & 5.1 & 56.7 & 38.1 & 100 \\
\hline & Female & $\mathrm{n}$ & 18 & 167 & 130 & 315 \\
\hline & & $\%$ & 5.7 & 53.0 & 41.3 & 100 \\
\hline \multirow{10}{*}{ Age group } & $18-29$ & $\mathrm{n}$ & 11 & 92 & 64 & 167 \\
\hline & & $\%$ & 6.6 & 55.1 & 38.3 & 100 \\
\hline & $30-39$ & $\mathrm{n}$ & 8 & 89 & 59 & 156 \\
\hline & & $\%$ & 5.1 & 57.1 & 37.8 & 100 \\
\hline & $40-49$ & $\mathrm{n}$ & 7 & 71 & 46 & 124 \\
\hline & & $\%$ & 5.6 & 57.3 & 37.1 & 100 \\
\hline & $50-59$ & $\mathrm{n}$ & 4 & 49 & 48 & 101 \\
\hline & & $\%$ & 4.0 & 48.5 & 47.5 & 100 \\
\hline & $60+$ & $\mathrm{n}$ & 4 & 43 & 32 & 79 \\
\hline & & $\%$ & 5.1 & 54.4 & 40.5 & 100 \\
\hline \multirow{8}{*}{$\begin{array}{c}\text { Highest } \\
\text { Educational } \\
\text { Level }\end{array}$} & Basic & $\mathrm{n}$ & 6 & 29 & 23 & 58 \\
\hline & & $\%$ & 10.3 & 50.0 & 39.7 & 100 \\
\hline & Middle & $\mathrm{n}$ & 16 & 166 & 107 & 289 \\
\hline & & $\%$ & 5.5 & 57.5 & 37.0 & 100 \\
\hline & Tertiary/University & $\mathrm{n}$ & 11 & 127 & 104 & 242 \\
\hline & & $\%$ & 4.5 & 52.5 & 43.0 & 100 \\
\hline & Postgraduate & $\mathrm{n}$ & 1 & 22 & 15 & 38 \\
\hline & & $\%$ & 5.4 & 54.9 & 39.7 & 100 \\
\hline \multirow{8}{*}{ Place of birth } & $\begin{array}{l}\text { Buenos Aires and } \\
\text { Surroundings }\end{array}$ & $\mathrm{n}$ & 25 & 243 & 164 & 432 \\
\hline & & $\%$ & 5.8 & 56.2 & 38.0 & 100 \\
\hline & Other city Argentina & $\mathrm{n}$ & 4 & 58 & 52 & 114 \\
\hline & & $\%$ & 3.5 & 50.9 & 45.6 & 100 \\
\hline & Other country & $\mathrm{n}$ & 1 & 33 & 26 & 60 \\
\hline & & $\%$ & 1.7 & 55.0 & 43.3 & 100 \\
\hline & No Information & $\mathrm{n}$ & 4 & 10 & 7 & 21 \\
\hline & & $\%$ & 19.1 & 47.6 & 33.3 & 100 \\
\hline \multirow{2}{*}{ Children } & No & $\mathrm{n}$ & 18 & 180 & 114 & 312 \\
\hline & & $\%$ & 5.8 & 57.7 & 36.5 & 100 \\
\hline
\end{tabular}




\begin{tabular}{|c|c|c|c|c|c|c|}
\hline \multirow{2}{*}{ Children } & & $\mathrm{n}$ & 16 & 164 & 135 & 315 \\
\hline & Yes & $\%$ & 5.1 & 52.1 & 42.9 & 100 \\
\hline \multirow{12}{*}{$\begin{array}{l}\text { Employment } \\
\text { type }\end{array}$} & Employer & $\mathrm{n}$ & 3 & 31 & 27 & 61 \\
\hline & & $\%$ & 4.9 & 50.8 & 44.3 & 100 \\
\hline & Employee & $\mathrm{n}$ & 18 & 188 & 138 & 344 \\
\hline & & $\%$ & 5.2 & 54.7 & 40.1 & 100 \\
\hline & Independent worker & $\mathrm{n}$ & 1 & 65 & 40 & 106 \\
\hline & & $\%$ & 0.9 & 61.3 & 37.7 & 100 \\
\hline & $\begin{array}{c}\text { Housekeeping/worker } \\
\text { without salary }\end{array}$ & $\mathrm{n}$ & 4 & 14 & 7 & 25 \\
\hline & & $\%$ & 16.0 & 56.0 & 28.0 & 100 \\
\hline & Retired/pensioned & $\mathrm{n}$ & 1 & 19 & 13 & 33 \\
\hline & & $\%$ & 3.0 & 57.6 & 39.4 & 100 \\
\hline & Unemployed & $\mathrm{n}$ & 7 & 27 & 24 & 58 \\
\hline & & $\%$ & 12.1 & 46.6 & 41.4 & 100 \\
\hline \multirow{4}{*}{ Salary } & No & $\mathrm{n}$ & 11 & 41 & 31 & 83 \\
\hline & & $\%$ & 13.3 & 49.4 & 37.3 & 100 \\
\hline & Yes & $\mathrm{n}$ & 23 & 303 & 218 & 544 \\
\hline & & $\%$ & 4.2 & 55.7 & 40.1 & 100 \\
\hline
\end{tabular}

ployment categories in terms of receiving salary versus not receiving salary. The second chi-squared analysis found a clear significant difference between the two groups $\left(\chi^{2}=11.47, \mathrm{df}=2, p=.003\right)$, such that the proportion of individuals without salary was three times as likely to be in the languishing group (13.3\%) as compared to the group receiving salary.

\subsection{Mental Health Classification and Specific Mental Disorders}

The classification of mental disorder was based on the SCL-90-R risk cut-off points (Derogatis, 1977). This instrument scores dimensions based on a mean of $\mathrm{T}=50$ and a deviation of $\mathrm{T}=10$. Those individuals who scored higher than the cutoff point T63 on the SCL-90-R dimensions are considered to belong to the specific mental disorder group. Five main groups of scale symptoms were included in this study: depression, anxiety, somatization, phobic anxiety, and obsessions and compulsions. Although the SCL-90-R includes other symptom scales, we selected those more closely related to DSM categories. Results are presented in Table 2. Only a small proportion of participants had significant symptomatology to be included in a clinical group. Of the sample, $6.4 \%$ had significant depressive symptoms, and within this group, only $5 \%$ were flourishing and $32.5 \%$ were languishing. It was found that individuals with depression were 9 times more likely to be languishing as compared to non-depressed individuals $\left(\chi^{2}=71.19, \mathrm{df}=2, p<.01\right)$. In addition, depressed individuals were 8 times less 
likely to be flourishing than were non-depressed participants.

Participants with anxious symptomatology (5.4\% of the sample) were 4 times more likely to be languishing (20.6\%) and nearly 3 times less likely to be flourishing than were Argentinean adults with low levels of anxiety $\left(\chi^{2}=23.39, \mathrm{df}=\right.$ $2, p<.01)$. However, when the symptomatology was related to phobic anxiety (8.8\% of the sample), the difference with the non-phobic group was less dramatic than were the results with the general anxiety group. Participants with phobic symptoms were 2 times more likely to be languishing, though a significant proportion $(23.6 \%)$ was flourishing $\left(\chi^{2}=10.70, \mathrm{df}=2, p<.01\right)$.

The $6.7 \%$ of Argentinean adults who showed somatic symptomatology presented the highest concentration $(83.3 \%)$ in the moderate mental health category $\left(\chi^{2}=17.23, \mathrm{df}=2, p<.01\right)$. Only a small proportion of participants in this clinical group was classified as either languishing (7.1\%) or flourishing (9.5\%).

Individuals with obsessive compulsive symptomatology (5.9\% of the sample) were 3 times more likely to be languishing and 3 times less likely to be flourishing than were the non-clinical group $\left(\chi^{2}=19.07, \mathrm{df}=2, p<.01\right)$.

When we considered those adults with comorbid disorders (two to five disorders), they were 8 times more likely to be languishing and 5 times less likely to be flourishing than were individuals without mental disorders $\left(\chi^{2}=58.30, \mathrm{df}=2\right.$, $p<.01)$.

\subsection{Dual-Continua Model Classification}

Those who scored higher than the cutoff point T63 on any of the five SCL-90-R dimensions considered in this study (depression, anxiety, somatization, phobic anxiety, and obsessions and compulsions) comprised the group with mental disorders $(\mathrm{n}=114)$. The comorbidity with a second disorder or more was taken into consideration $(\mathrm{n}=49)$ to estimate the number of participants in this group, which represented $18.2 \%$ of the sample. Results are shown in Table 4.

The category moderate mental health (with no mental illness; $42.6 \%$ ) was the one with the highest concentration of individuals. Second in importance was the flourishing category (36.5\%), indicating very good mental health of Argentinean adults. A smaller group of Argentinean adults (2.7\%) were pure languishing (with no mental illness).

Among those individuals with mental disorders, a significant proportion $(82.5 \%)$ was classified in the mental illness and moderate mental health category (12.3\% of the total sample) while a small proportion of this group was also

Table 4. Dual-continua diagnosis assessment in Argentinean adults $(\mathrm{N}=627)$.

\begin{tabular}{|c|c|c|c|c|c|c|}
\hline & $\begin{array}{c}\text { Mental } \\
\text { Illness and } \\
\text { Languishing }\end{array}$ & Languishing & $\begin{array}{c}\text { Mental } \\
\text { Illness and } \\
\text { Mod. MH }\end{array}$ & $\begin{array}{c}\text { Mod Mental } \\
\text { Health }\end{array}$ & $\begin{array}{c}\text { Mental } \\
\text { Illness and } \\
\text { Flourishing }\end{array}$ & Flourishing \\
\hline $\mathrm{n}$ & 17 & 17 & 77 & 267 & 20 & 229 \\
\hline$\%$ & 2.7 & 2.7 & 12.3 & 42.6 & 3.2 & 36.5 \\
\hline
\end{tabular}


languishing (2.7\% of the total sample). Only a very small group of flourishing individuals had a concurrent mental disorder (3.2\%), which is consistent with the dual-continua model (Keyes, 2005).

It is important to remark that among individuals who were languishing, 50\% had a mental disorder while among those with moderate mental health, $22.4 \%$ had a mental disorder, and among those who were flourishing, only $8 \%$ had a mental disorder.

\section{Discussion}

This study aimed to evaluate the mental health status of a sample of Argentinean adults. Findings showed Argentinean adults to have very good mental health. A high proportion of adults had flourishing mental health (39.7\%). In addition, only a minority had languishing mental health (5.7\%). The prevalence of flourishing was high compared to findings from most previous studies (Karaś et al., 2014; Keyes, 2005; Lamers et al., 2011; Lim et al., 2013; Petrillo et al., 2015), but similar to the Chinese adult sample (Yin et al., 2013). Nevertheless, a few studies showed even higher rates (Gilmour, 2014; Salama-Younes, 2011). In other words, mental health status shows wide variation across cultures and the proportion of flourishing and languishing individuals are not universal. While Keyes (2005) pointed out that only a small proportion of American adults are flourishing (18\%), and a similar proportion are languishing, in our study, we found two times more flourishing Argentinean adults and three times fewer languishing individuals. Many variables may affect the prevalence of mental health such as the way the economy operates in a specific country, the public safety, the political system, healthcare, education and the public spaces to which people have access, among other things (Ateca-Amestoy, Aguilar, \& Moro-Egido, 2014). Methodological issues could also be responsible of such divergences, for instance our study is based on an urban sample of adults of the major city of Argentina with easy access to health and educational services. In addition, some response bias could also affect the report of well-being. Diener et al. (2010) in a cross cultural study reported that Latin Americans exhibited high desirability for life satisfaction, as well as a strong positivity bias (Diener, Kahneman, \& Helliwell, 2010), which could contribute to the high rate flourishing mental health.

Another aim of this study was to compare mental health based on demographic variables. Although no differences were found by employment type, a higher mental health level was found in Argentinean adults who received any sort of salary compared with those who, due to unemployment or housework, did not receive any. Not receiving salary has been consistently associated with lower levels of mental health in American, Canadian, and Korean adults (Gilmour, 2014; Keyes, 2005; Lim et al., 2013). In addition, this variable has been consistently associated to lower levels of emotional well-being (satisfaction with life, happiness) in other Argentinean studies using national samples (Ciocchini, Molteni, \& Brenlla, 2010; De Santis \& Villagra Torcomian, 2014). Not having income may be an important limitation in a person's life, particularly in a de- 
veloping country, because, in many cases, it directly affects the access to basic needs, such, as food, shelter, or health care (Diener, Suh, Lucas, \& Smith, 1999).

In relation to the other demographic variables, we found a similar level of mental health between men and women, age groups, and across those who had children and those who did not. Although higher education had been associated with higher levels of mental health in many previous studies (Karaś et al., 2014; Keyes \& Lopez, 2002; Lim et al., 2013; Yin et al., 2013), we did not find this relationship. The fact of having a higher education could indirectly relate to a higher income. The same studies that found an association between educational level and mental health, reported a higher level of mental health in adults with higher incomes. However, in this study, income level was not included among variables due to the consistent reluctance of many Argentinean people to provide such information in surveys or researches (Salvia \& Donza, 1999).

When we considered specific mental disorders, we found that having any mental disorder decreased significantly the mental health status, and individuals were more languishing and less flourishing in all mental disorder categories considered in this study (depression, anxiety, obsession and compulsion, phobic anxiety, somatization). Depression was the clinical disorder that showed the most significant effect on mental health classification, followed by general anxiety disorder. The comorbidity with a second disorder showed a higher proportion of individuals with poorer mental health as compared to general anxiety alone. Our findings are consistent with previous studies in Canada and the US (Gilmour, 2014; Keyes, 2005): individuals with a mental disorder are classified in lower mental health categories. It should be noted that no severe mental disorder, such as psychotic or bipolar disorders, was included in this study, which could explain why individuals with mental disorders in this sample showed moderate mental health as opposed to languishing.

Overall, a significant proportion of Argentinean adults presented important symptomatology compatible with mental disorders (18.2\%); among them, individuals were mainly classified as having moderate mental health or languishing. Consistent with previous findings in Chinese, Canadian, and US adults, and with the dual-continua model (Gilmour, 2014; Keyes, 2005; Keyes, 2007; Yin et al., 2013), a small percentage of individuals who presented mental disorders were also flourishing (3.2\%). Almost 4 of 10 Argentinean adults had complete mental health, which corresponds to individuals with flourishing mental health and the absence of mental disorders. Our results support the assumption of the dual-continua model that individuals free of mental illness are clearly not a homogenous group, and do not necessarily function in the same or a better manner as compared to individuals with mental disorders (Keyes, 2005). In other words, there was an $81.8 \%$ of the sample without mental disorders but only $36.5 \%$ had also high mental health. Mental health promotion should aim at individuals with mental disorders but also at those without mental disorders and languishing and moderate mental health in order to pursuit a flourishing life. Longitudinal studies have shown that flourishing mental health reduced the incidence of mental 
illnesses, particularly mood and anxiety disorders, in adult population (Keyes et al., 2010; Schotanus-Dijkstra, ten Have, Lamers, de Graaf, \& Bohlmeijer, 2016).

Some limitations should be mentioned. First, we used a self-report instrument to assess the severity of psychiatric symptomatology. Although this type of instrument tends to overestimate the prevalence of mental disorders, and further, does not allow for accurate diagnosis, as structured interviews do, it does provide a good approximation of its presence (McDermut \& Zimmerman, 2005). Thus, future studies might benefit from assessing mental disorders with structured interviews to provide a complete diagnosis. Second, a self-report scale was used to evaluate mental health. Future studies may include hetero-reports on emotional, psychological, and social well-being from experts or family members. Third, we only considered five mental disorders in this study. It is necessary for future research to consider other disorders to assess a wider spectrum of mental disorders. Finally, we used an intentional sample consisting mostly of individuals living in Buenos Aires and surroundings, and thus, there is an under-representation of other regions of Argentina. Future studies should include adults from other regions of Argentina, including small towns and rural areas, in order to evaluate the applicability of these results to the whole population.

\section{Conclusion}

In summary, this research provides the first Latin American study on the mental health continuum prevalence and the dual-continue classification. There were several international studies of this model in other regions but Latin America had not been included. The results showed evidence of good mental health in a sample of Argentinean adults and support previous findings on the dual-continue model. The assessment of mental health status is essential to promote mental health in order to develop well-being and achieve flourishing in the population.

\section{References}

Ateca-Amestoy, V., Aguilar, A. C., \& Moro-Egido, A. I. (2014). Social Interactions and Life Satisfaction: Evidence from Latin America. Journal of Happiness Studies, 15, $527-$ 554. https://doi.org/10.1007/s10902-013-9434-y

Casullo, M. M. (2004). Síntomas psicopatológicos en adultos urbanos [Psychopathological Symptoms in Urban Adults]. Psicología y Ciencia Social, 6, 49-57.

Ciocchini, F. J., Molteni, G. R., \& Brenlla, M. (2010). Bienestar subjetivo en la Argentina durante el período 2005-2007: Determinantes de la felicidad, según la Encuesta de la Deuda Social Argentina (EDSA) [Subjective Well-Being in Argentina during the Period 2005-2007: Determinants of Happiness, According to the Social Debt Survey Argentina]. Revista de Psicología, 6, 41-65.

De Santis, M., \& Villagra Torcomian, I. (2014). Condiciones económicas y capital social como determinantes de la salud y el bienestar subjetivo. El caso de Argentina durante 1995 y 2006 [Economic Conditions and Social Capital as Determinants of Health and Subjective Well-Being. The Case of Argentina during 1995 and 2006]. Cuadernos de Economía, 33, 543-567. https://doi.org/10.15446/cuad.econ.v33n63.45346

Derogatis, L. (1977). SCL-90-R Administration, Scoring and Procedures Manual-II. 
Towson, MD: Clinical Psycometric Research.

Diener, E., Wirtz, D., Tov, W., Kim-Prieto, C., Choi, D.-W., Oishi, S., \& Biswas-Diener, R. (2010). New Well-Being Measures: Short Scales to Assess Flourishing and Positive and Negative Feelings. Social Indicators Research, 97, 143-156. https://doi.org/10.1007/s11205-009-9493-y

Diener, E., Kahneman, D., \& Helliwell, J. (2010). International Differences in Well-Being. Oxford: Oxford University Press. https://doi.org/10.1093/acprof:oso/9780199732739.001.0001

Diener, E., Suh, E. M., Lucas, R. E., \& Smith, H. L. (1999). Subjective Well-Being: Three Decades of Progress. Psychological Bulletin, 125, 276-302. https://doi.org/10.1037/0033-2909.125.2.276

Gallagher, M. W., Lopez, S. J., \& Preacher, K. J. (2009). The Hierarchical Structure of Well-Being. Journal of Personality, 77, 1025-1050. https://doi.org/10.1111/j.1467-6494.2009.00573.x

Gilmour, H. (2014). Positive Mental Health and Mental Illness. Health Reports, 25, 3-9.

Huppert, F., \& So, T. C. (2013). Flourishing across Europe: Application of a New Conceptual Framework for Defining Well-Being. Social Indicators Research, 110, 837-861. https://doi.org/10.1007/s11205-011-9966-7

Joshanloo, M., Wissing, M. P., Khumalo, I. P., \& Lamers, S. M. A. (2013). Measurement Invariance of the Mental Health Continuum-Short Form (MHC-SF) across Three Cultural Groups. Personality and Individual Differences, 55, 755-759.

https://doi.org/10.1016/j.paid.2013.06.002

Karaś, D., Cieciuch, J., \& Keyes, C. L. M. (2014). The Polish Adaptation of the Mental Health Continuum-Short Form (MHC-SF). Personality and Individual Differences, 69, 104-109. https://doi.org/10.1016/j.paid.2014.05.011

Keyes, C. L. M. (2005). Mental Illness and/or Mental Health? Investigating Axioms of the Complete State Model of Health. Journal of Consulting and Clinical Psychology, 73, 539-548. https://doi.org/10.1037/0022-006X.73.3.539

Keyes, C. L. M. (2007). Promoting and Protecting Mental Health as Flourishing: A Complementary Strategy for Improving National Mental Health. The American Psychologist, 62, 95-108. https://doi.org/10.1037/0003-066X.62.2.95

Keyes, C. L. M., Dhingra, S. S., \& Simoes, E. J. (2010). Change in Level of Positive Mental Health as a Predictor of Future Risk of Mental Illness. American Journal of Public Health, 100, 2366-2371. https://doi.org/10.2105/AJPH.2010.192245

Keyes, C. L. M., Eisenberg, D., Perry, G. S., Dube, S. R., Kroenke, K., \& Dhingra, S. S. (2011). The Relationship of Level of Positive Mental Health with Current Mental Disorders in Predicting Suicidal Behavior and Academic Impairment in College Students. Journal of American College Health, 60, 126-133. https://doi.org/10.1080/07448481.2011.608393

Keyes, C. L. M., \& Grzywacz, J. G. (2005). Health as a Complete State: The Added Value in Work Performance and Healthcare Costs. Journal of Occupational and Environmental Medicine, 47, 523-532. https://doi.org/10.1097/01.jom.0000161737.21198.3a

Keyes, C. L. M., \& Lopez, S. J. (2002). Toward a Science of Mental Health: Positive Directions in Diagnosis and Interventions. In S. J. Lopez, \& C. R. Snyder (Eds.), Handbook of Positive Psychology (pp. 45-59). New York: Oxford University Press.

Keyes, C. L. M., \& Simoes, E. J. (2012). To Flourish or Not: Positive Mental Health and All-Cause Mortality. American Journal of Public Health, 102, 2164-2172. https://doi.org/10.2105/AJPH.2012.300918

Keyes, C. L. M., Wissing, M., Potgieter, J. P., Temane, M., Kruger, A., \& van Rooy, S. 
(2008). Evaluation of the Mental Health Continuum-Short Form (MHC-SF) in Setswana-Speaking South Africans. Clinical Psychology \& Psychotherapy, 15, 181-192. https://doi.org/10.1002/cpp.572

Lamers, S. M. A., Westerhof, G. J., Bohlmeijer, E. T., ten Klooster, P. M., \& Keyes, C. L. M. (2011). Evaluating the Psychometric Properties of the Mental Health ContinuumShort Form (MHC-SF). Journal of Clinical Psychology, 67, 99-110. https://doi.org/10.1002/jclp.20741

Lim, Y.-J., Ko, Y.-G., Shin, H.-C., \& Cho, Y. (2013). Prevalence and Correlates of Complete Mental Health in the South Korean Adult Population. In C. L. M. Keyes (Ed.), Mental Well-Being (pp. 91-109). Berlin: Springer. https://doi.org/10.1007/978-94-007-5195-8 5

Lupano Perugini, M. L., De la Iglesia, G., Castro Solano, A., \& Keyes, C. L. M. (2016). The Mental Health Continuum-Short Form (MHC-SF) in the Argentinean Context: Confirmatory Factor Analysis and Measurement Invariance. Europe's Journal of Psychology, Online.

Machado, W. D. L., \& Bandeira, D. R. (2015). Positive Mental Health Scale: Validation of the Mental Health Continuum-Short Form. Psico-USF, 20, 259-274. https://doi.org/10.1590/1413-82712015200207

McDermut, W., \& Zimmerman, M. (2005). Assessment Instruments and Standardized Evaluation. In J. Oldham, A. Skodol, \& D. Bender (Eds.), The American Psychiatric Publishing Textbook of Personality Disorders (pp. 89-101). Arlington, VA: American Psychiatric Publishing.

Petrillo, G., Capone, V., Caso, D., \& Keyes, C. L. M. (2015). The Mental Health Continuum-Short Form (MHC-SF) as a Measure of Well-Being in the Italian Context. Social Indicators Research, 121, 291-312. https://doi.org/10.1007/s11205-014-0629-3

Robitschek, C., \& Keyes, C. L. M. (2009). Keyes's Model of Mental Health with Personal Growth Initiative as a Parsimonious Predictor. Journal of Counseling Psychology, 56, 321-329. https://doi.org/10.1037/a0013954

Ryff, C. D. (1989). Happiness Is Everything, or Is It? Explorations on the Meaning of Psychological Well-Being. Journal of Personality and Social Psychology, 57, 1069-1081. https://doi.org/10.1037/0022-3514.57.6.1069

Salama-Younes, M. (2011). Positive Mental Health, Subjective Vitality and Satisfaction with Life for French Physical Education Students. World Journal of Sport Sciences, 4, 90-97.

Salvia, A., \& Donza, E. (1999). Problemas de medición y sesgos de estimación derivados derivados de la no respuesta a preguntas de ingresos en la EPH (1990-1998) [Measurement Problems and Estimation Biases Derived from Non-Response to Income Questions in the EPH (1990-1998)]. Asociación Argentina de Especialistas de Estudios del Trabajo, No. 18, 93-120.

Sanchez, R. O., \& Ledesma, R. D. (2009). Análisis Psicométrico del Inventario de Síntomas Revisado (SCL-90-R) en Población Clínica [Psychometric Analysis of the Revised Symptom Checklist (SCL-90-R)]. Revista Argentina de Clinica Psicologica, 18, 265-274.

Seligman, M. E. P. (2011). Flourish: A Visionary New Understanding of Happiness and Well-Being. New York: Free Press.

Schotanus-Dijkstra, M., ten Have, M., Lamers, S. M. A., de Graaf, R., \& Bohlmeijer, E. T. (2016). The Longitudinal Relationship between Flourishing Mental Health and Incident Mood, Anxiety and Substance Use Disorders. The European Journal of Public Health, Online. https://doi.org/10.1093/eurpub/ckw202

Westerhof, G., \& Keyes, C. L. M. (2010). Mental Illness and Mental Health: The Two 
Continua Model across the Lifespan. Journal of Adult Development, 17, 110-119. https://doi.org/10.1007/s10804-009-9082-y

Yin, K., He, J., \& Fu, Y. (2013). Positive Mental Health: Measurement, Prevalence, and Correlates in a Chinese Cultural Context. In C. L. M. Keyes (Ed.), Mental Well-Being (pp. 111-132). Berlin: Springer. https://doi.org/10.1007/978-94-007-5195-8 6

Submit or recommend next manuscript to SCIRP and we will provide best service for you:

Accepting pre-submission inquiries through Email, Facebook, LinkedIn, Twitter, etc. A wide selection of journals (inclusive of 9 subjects, more than 200 journals)

Providing 24-hour high-quality service

User-friendly online submission system

Fair and swift peer-review system

Efficient typesetting and proofreading procedure

Display of the result of downloads and visits, as well as the number of cited articles Maximum dissemination of your research work

Submit your manuscript at: http://papersubmission.scirp.org/

Or contact psych@scirp.org 